\title{
HIV/AIDS-associated visceral leishmaniasis in patients from an endemic area in Central-west Brazil
}

\author{
Priscilla Alexandrino-de-Oliveira, ${ }^{1,2}$, Joanna Reis Santos-Oliveira', Maria Elizabeth Cavalheiros Dorval ${ }^{3}$, \\ Francisco das Chagas Brandão Da-Costa ${ }^{4}$, Gracy Regina Oliveira Leite Pereira ${ }^{2}$, \\ Rivaldo Venâncio da Cunha ${ }^{5}$, Anamaria Mello Miranda Paniago ${ }^{5}$,Alda Maria Da-Cruz ${ }^{1 /+}$
}

\footnotetext{
${ }^{1}$ Laboratório Interdisciplinar de Pesquisas Médicas, Instituto Oswaldo Cruz-Fiocruz, Av. Brasil 4365, 21045-900 Rio de Janeiro, RJ, Brasil

${ }^{2}$ Hospital Universitário ${ }^{3}$ Departamento de Patologia ${ }^{5}$ Departamento de Clínica Médica, Universidade Federal do Mato Grosso do Sul, Campo Grande, MS, Brasil ${ }^{4}$ Centro de Doenças Infecciosas e Parasitárias, Prefeitura Municipal de Campo Grande, Campo Grande, MS, Brasil
}

An increase in morbidity associated with visceral leishmaniasis (VL) in human immunodeficiency virus (HIV)/ AIDS patients has been described in Africa and the Mediterranean. Despite the high endemicity of VL and HIV-1/ AIDS in Brazil, this association has not been thoroughly investigated. Our aim was to evaluate the epidemiologic and clinical characteristics of VL-HIV-1/AIDS cases from Central-west [Mato Grosso do Sul (MS)] Brazil. Medical records of $23 \mathrm{VL}-H I V-1 / A I D S$ patients were reviewed. Patients were predominantly adult males (87\%) and $34.8 \%$ of the patients were intravenous drug users (IVDU). Leishmaniasis was the first opportunistic infection in $60 \%$ of the HIV-1 patients. Fever occurred in all patients, although splenomegaly and hepatomegaly were absent in $21.7 \%$ of the cases. CD4 $4^{+}$-cell counts were below 200 cells $/ \mathrm{mm}^{3}$ in $80 \%$ of the cases and the counts did not increase after clinical remission despite antiretroviral therapy. The first drug chosen to treat the cases was antimonial, but the therapeutic regimen was altered to amphotericin B in 12 of 17 cases due to side effects. Relapses were reported in 56.5\% of the patients. IVDU may constitute an important risk factor for the transmission of both diseases in MS. VL-HIV-1/AIDS patients in MS share similar clinical characteristics as those from other endemic regions worldwide. Thus, these findings are critical for improving the surveillance of VL-HIVIAIDS patients.

Key words: HIV/AIDS - opportunistic infection - Brazil - visceral leishmaniasis - intravenous drug users - recurrence

New immunopathological aspects of visceral leishmaniasis (VL), also known as kala-azar, associated with human immunodeficiency virus (HIV) infection have been reported, particularly for patients in Europe and Africa where the disease has emerged as an important opportunistic infection (Alvar et al. 1997, 2008, Cruz et al. 2006, ter Horst et al. 2008). The diagnosis of leishmaniasis, especially in co-infected individuals, continues to challenge physicians because VL shares similarities with other diseases included in the AIDS surveillance case definition, such as histoplasmosis, disseminated coccidioidomycosis or extrapulmonary tuberculosis (MS 2004a).

The cellular immune response is considered the main mechanism of defence against Leishmania sp. infection. Depending on the immunological status of the host, infection evolves either to spontaneous regression or to a

Financial support: UFMS, Programa Nacional de DST/AIDS/MS (ED00095/2007), IOC, CNPq, FAPERJ (E-26/103-111/2008)

+ Corresponding author: alda@ioc.fiocruz.br

Received 12 January 2010

Accepted 13 May 2010 progressive disease (Olivier et al. 2003). Although VL is not considered an illness-defining case, HIV/AIDS patients are at high risk for this co-infection (Alvar et al. 1997, 2008). Compared to those who received no antiretroviral therapy, patients treated with highly active antiretroviral therapy (HAART) had a 59\% reduction of risk for developing the disease (del Giudice et al. 2002). However, HAART did not prevent relapses in the HIV/ AIDS patients who developed VL (Laguna 2003).

In Brazil, the most important Leishmania species causing VL is Leishmania (Leishmania) infantum chagasi. The endemicity of VL in many Brazilian regions is high, but few reports have addressed the clinical features of HIV/AIDS-associated VL (Borges et al. 1999, Orsini et al. 2002, Rabello et al. 2003, Daher et al. 2009). Although the HIV/AIDS National Surveillance Program has been considered a success, HIV is still spreading in Brazil and reaching small cities; also, an urbanization of human leishmaniasis has been observed, resulting in an overlap of these two diseases (Rabello et al. 2003).

Much of the knowledge about HIV/AIDS-associated VL comes mainly from European studies (Cacopardo et al. 1996, del Giudice et al. 2002, Pasquau et al. 2005, Marques et al. 2007). Brazil, however, is a country that exhibits particular epidemiological features related to Leishmania species, to vectors involved in infection transmission and to at-risk populations, which can influence clinical course and therapeutic response. In this scenario, defining the clinical outcome of VL-HIV/AIDS in different regions of Brazil is of critical importance. 
In the last decade, Mato Grosso do Sul (MS), in Central-west Brazil, has emerged as an important endemic area for VL because of the increasing number and severity of reported cases (Oliveira et al. 2006) of this disease. Moreover, there is a high prevalence of AIDS in MS. In the present study, the aim was to evaluate a series of VLHIV/AIDS cases from this region and to describe their epidemiological and clinical characteristics.

\section{PATIENTS, MATERIALS AND METHODS}

Patients - We reviewed the medical records of 30 HIV-1/AIDS patients who were clinically suspected of having VL between January 2000-December 2006. The inclusion criteria included the detection of Leishmania parasites in HIV-1 patients with clinical suspicion of VL. Twenty-three of the 30 reviewed cases fulfilled these criteria and were included in this descriptive study. The following data were obtained by reviewing the clinical charts of these patients: demographic information (sex, age and geographical origin), category of HIV exposure, year of VL and HIV-1/AIDS diagnoses, clinical signs and symptoms, methods of parasitological diagnosis, laboratory tests, leishmaniasis treatment, antiretroviral therapy, T-cell counts, HIV plasma viral load and clinical outcome.

Diagnosis criteria, clinical outcome and anti-leishmanial therapy - According to the Brazilian Ministry of Health, HIV/AIDS patients were those with both a positive enzyme immunoassay and western blot assay for HIV and CD4 ${ }^{+} \mathrm{T}$-lymphocyte counts under 350 cells $/ \mathrm{mm}^{3}$ (MS 2004b). VL diagnosis was determined by detecting parasites in the bone marrow (promastigote forms of Leishmania in Novy-MacNeal-Nicolle culture medium or amastigotes visualized in Giemsa-stained smears of cells obtained from a bone marrow aspirate). Fever was defined as an axillary temperature greater than $37.8^{\circ} \mathrm{C}$. Leucopenia was defined as a leukocyte count of less than $3.000 \mathrm{~mm}^{3}$. Anaemia was defined as haemoglobin concentration of less than $10 \mathrm{~g} / \mathrm{dL}$. Thrombocytopenia was defined as platelet counts of less than $120.000 \mathrm{~mm}^{3}$. Albumin/globulin ratio was considered inverted when it was less than one.

Absolute counts of $\mathrm{CD}^{+}$and $\mathrm{CD} 8^{+} \mathrm{T}$-lymphocytes were determined using BD Tritest ${ }^{\circledR}$ monoclonal antibodies specific for CD4, CD8 and CD3, conjugated to FITC, $\mathrm{PE}$ and PerCP, respectively, and a BDTrue Count ${ }^{\circledR}$ reagent kit (BD Biosciences, Franklin Lakes, NJ, USA), according to the manufacturer's instructions. Samples were acquired using a FACSCalibur ${ }^{\circledR}$ (BD, USA) and analyzed by Multiset ${ }^{\circledR}$ software (BD, USA). HIV RNA copies in the plasma (viral load) were quantified by the nucleic acid sequence-based amplification technique (NASBA $^{\circledR}$ Organon Teknica, Boxtel, Holland) and the lower limit of detection was 400 copies $/ \mathrm{mL}$.

Evidence for a favorable response to therapy (clinical remission) was considered when the patient was afebrile and when physical signs as well as laboratory abnormalities either subsided or significantly improved after a complete course of treatment. Therapeutic failure was considered when the patient had a persistence of clinical symptoms, laboratory records that remained unchanged and death due to leishmaniasis or related complications. Relapse of VL was defined as a new episode after successful treatment, which was confirmed microbiologically by the detection of Leishmania amastigotes in the bone marrow, irrespective of time of anti-leishmanial treatment discontinuation.

Ethics - The study was approved by the Ethical Committee of the Universidade Federal do Mato Grosso do Sul (register 897). Informed consent was obtained from all patients.

\section{RESULTS}

The 23 participants in this study lived in MS and had not recently travelled outside the state. The majority of patients came from urban areas (17 cases from the MS capital, Campo Grande, and 2 cases from Corumbá). The median age was 37 years (range 21-56 years); 20 patients (87\%) were male and eight (34.8\%) had intravenous drug use as their HIV transmission category. In 10 cases (43\%), VL and HIV were diagnosed at the same time. Five cases had a VL diagnosis between 1-5 years after HIV diagnosis, while eight presented with VL five or more years after HIV diagnosis. Viscerotropic Leishmania was the first opportunistic infection in 14 cases (60.1\%). Fever occurred in all the patients, while splenomegaly and hepatomegaly were absent in $21.7 \%$ of the cases. Only $39.1 \%$ lost over $10 \mathrm{~kg}$ of body weight. In the 23 cases from which parasites were isolated by culture, $20(87 \%)$ had amastigotes directly visualized in the cells of the bone marrow smears (Table I). Different degrees of anaemia, leucopoenia, thrombocytopenia and abnormal serum levels of albumin and globulin were also noted (Table I).

The CD4 ${ }^{+} \mathrm{T}$-cell counts were very low (median 44.5 cells $/ \mathrm{mm}^{3}$, range $5-460$ cells $/ \mathrm{mm}^{3}, \mathrm{n}=20$ ) and most patients $(80 \%)$ were in an advanced immunosuppressive state (less than 200 cells $/ \mathrm{mm}^{3}$ ). Only eight $(34.8 \%$ ) out of 23 patients were receiving HAART (2 nucleoside reverse transcriptase inhibitors and 1 non-nucleoside reverse transcriptase inhibitors or 1 protease inhibitor) at the time of VL diagnosis. Despite HAART, plasma HIV viral load was high, over log three copies $/ \mathrm{mL}$ in $87.5 \%$ of the patients, whereas only one out of eight cases presented with a suppressed plasma HIV viral load during the VL episode (Table I).

Meglumine antimonial (20 mg/kg/day for 30 days) was the first-choice drug for 17 patients and 12 of them had the therapeutic regimen altered to amphotericin B. Side effects led to a change in the therapeutic regimen in these 12 patients, especially those who had amylase levels higher than $123 \mathrm{UI} / \mathrm{mL}$ ( 7 cases). Four cases were treated only with amphothericin B $(0.7-1 \mathrm{mg} / \mathrm{kg}$ accumulated dose during 28 days). Two patients did not receive anti-leishmanial treatment. One or two relapses were found for 13 out of 23 patients. However, 10 patients (43.5\%) did not relapse up to one year after discontinuing anti-leishmanial therapy. Two patients died: one due to leishmaniasis a few hours after diagnosis and the other one due to an unrelated cause. 
TABLE I

Epidemiological, clinical and laboratorial findings of 23 patients with visceral leishmaniasis associated with AIDS in Campo Grande, Mato Grosso do Sul, Brazil 2000-2006

\begin{tabular}{|c|c|c|}
\hline Epidemiological, clinical and laboratorial characteristics & Frequency ${ }^{a} / \mathrm{n}$ & $\%$ \\
\hline \multicolumn{3}{|l|}{ Gender } \\
\hline Male & $20 / 23$ & 87 \\
\hline Female & $3 / 23$ & 13 \\
\hline \multicolumn{3}{|l|}{ Age in years } \\
\hline $20-40$ & $16 / 23$ & 69.6 \\
\hline $41-60$ & $7 / 23$ & 30.4 \\
\hline \multicolumn{3}{|l|}{ Transmission category } \\
\hline Intravenous drug user & $8 / 23$ & 34.8 \\
\hline Sexual & $21 / 23$ & 91.3 \\
\hline \multicolumn{3}{|l|}{ Clinical features } \\
\hline Fever & $23 / 23$ & 100 \\
\hline Splenomegaly & $18 / 23$ & 78.3 \\
\hline Hepatomegaly & $18 / 23$ & 78.3 \\
\hline Weight loss $\geq 10 \mathrm{Kg}$ & $9 / 23$ & 39.1 \\
\hline \multicolumn{3}{|l|}{ Laboratorial tests } \\
\hline Hemoglobin $\leq 10 \mathrm{~g} / \mathrm{dL}$ & $16 / 20$ & 80 \\
\hline$\geq 10 \mathrm{~g} / \mathrm{dL}$ & $4 / 20$ & 20 \\
\hline Leucocytes $>3,000 / \mathrm{mm}^{3}$ & $6 / 20$ & 30 \\
\hline$<3,000 / \mathrm{mm}^{3}$ & $14 / 20$ & 70 \\
\hline Platelets $>120,000 / \mathrm{mm}^{3}$ & $9 / 20$ & 45 \\
\hline$<120,000 / \mathrm{mm}^{3}$ & $11 / 20$ & 55 \\
\hline Albumin/globulin ratio - normal $(\geq 1)$ & $2 / 18$ & 11.1 \\
\hline - abnormal $(\leq 1)$ & $16 / 18$ & 89.9 \\
\hline \multicolumn{3}{|l|}{ Parasites - bone marrow cells smears } \\
\hline Giemsa stained smears - direct exam & $20 / 23$ & 87 \\
\hline Culture in Novy-MacNeal-Nicolle medium & $23 / 23$ & 100 \\
\hline \multicolumn{3}{|l|}{ Immunological status } \\
\hline $\mathrm{T} \mathrm{CD} 4^{+}$cells count $>200 / \mathrm{mm}^{3}$ & $4 / 20$ & 20 \\
\hline$<200 / \mathrm{mm}^{3}$ & $16 / 20$ & 80 \\
\hline Plasma viral load $>\log 3$ HIV RNA copies $/ \mathrm{mL}$ & $18 / 20$ & 94.7 \\
\hline$<\log 3$ HIV RNA copies $/ \mathrm{mL}$ & $1 / 20$ & 5.3 \\
\hline
\end{tabular}

$a$ : number of patients with positive results; HIV: human immunodeficiency virus; n: number of patients evaluated.

Six patients were evaluated two different times (active disease and clinical remission) (Table II). VL and HIV were diagnosed at the same time in three out of six patients and, because of this, only three were on HAART at the moment of $\mathrm{CD}^{+}{ }^{+}$T-cell count and HIV viral load evaluation. However, in the clinical remission phase of VL, all of these patients had already finished the antiLeishmania therapy and were receiving HAART. Despite the antiretroviral therapy, no significant increase in $\mathrm{CD}^{+}$ T-cells was found during clinical remission and the $\mathrm{CD}^{+}$ T-cell count remained under 200 cells $/ \mathrm{mm}^{3}$ (Figure) and at the same level as during active VL disease. The viral load levels for all these patients decreased significantly, but two of them still presented high HIV RNA copies $(\log 5)$. We also observed one relapse episode in four out of six patients and one patient experienced two episodes. Two co-infected patients presented with herpes zoster concomitant to anti-leishmanial therapy.

\section{DISCUSSION}

The development of the HIV/AIDS pandemic has modified the spectrum of leishmaniasis in the last 20 years in both clinical and epidemiological fields (Cruz et al. 2006, Alvar et al. 2008). The reported prevalence 
TABLE II

Laboratorial parameters for human immunodeficiency virus (HIV) infection evaluation in visceral leishmaniasis (VL) associated HIV infection patients

\begin{tabular}{|c|c|c|c|c|}
\hline \multirow{2}{*}{$\begin{array}{l}\text { Patients } \\
\text { number }\end{array}$} & \multicolumn{2}{|c|}{ Absolute counts of $\mathrm{CD}^{+} \mathrm{T}$ cells $\left(\mathrm{mm}^{3}\right)$} & \multicolumn{2}{|c|}{$\begin{array}{l}\text { HIV viral load levels } \\
\qquad(\log )\end{array}$} \\
\hline & Active phase & Remission phase & Active phase & Remission phase \\
\hline $1^{a}$ & 46 & 59 & 4.8 & 3.7 \\
\hline $2^{a}$ & 19 & 33 & NR & 5.5 \\
\hline 3 & 102 & 129 & 4.5 & 2.5 \\
\hline 4 & 44 & 61 & 4.4 & 2.2 \\
\hline 5 & 18 & 45 & 6.1 & 5.3 \\
\hline $6^{a}$ & 75 & 187 & NR & 1.8 \\
\hline
\end{tabular}

a: patients whose VL and HIV were diagnosed concomitantly; NR: not realized.
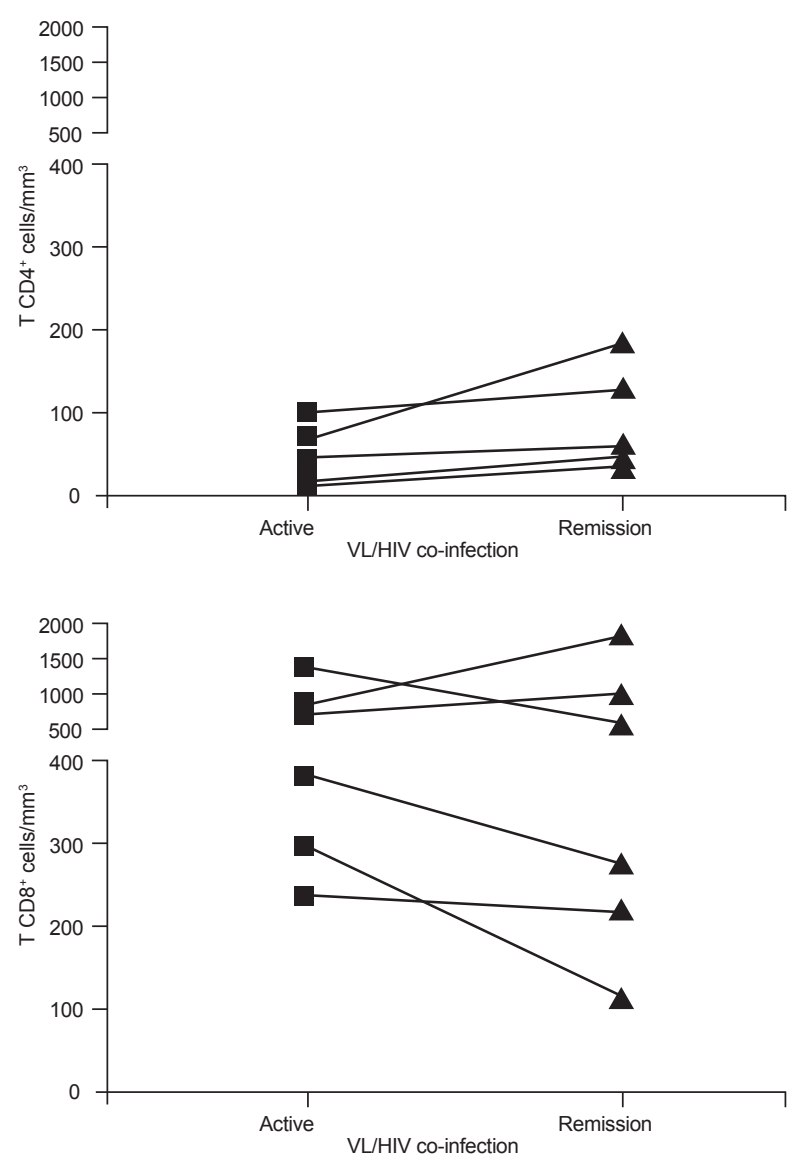

$\mathrm{CD}^{+}$and $\mathrm{CD} 8^{+} \mathrm{T}$ lymphocyte counts of visceral leishmaniasis (VL) human immunodeficiency virus (HIV)/AIDS-associated patients suffering from active VL disease ( $(\mathbf{\bullet})$ and during clinical remission $(\mathbf{\Lambda})$.

of HIV/AIDS-associated leishmaniasis has increased in Brazil (Rabello et al. 2003). The epidemiological characteristics of Leishmania and HIV co-infection can differ from one endemic region to another due to parasite strain, vector behavior or socio-environmental conditions of the exposed hosts. Here we described the main clinical and laboratorial features of parasitological confirmed cases of VL associated HIV/AIDS patients from endemic areas of $L$. infantum chagasi located in the Central-west region of Brazil.

The high incidence of VL in adult males may reflect the HIV infection patterns in Brazil (Rabello et al. 2003) and is similar to that found in patients from the Mediterranean basin (Cruz et al. 2006, Alvar et al. 2008). Additionally, some experimental models suggest that females might be less inclined to develop clinical symptoms of VL (Evans et al. 1992). The prevalence of intravenous drug users (IVDU) (34.8\%) among the patients studied here was higher than that reported for other Brazilian endemic regions (Rabello et al. 2003). In Europe, it is known that people sharing needles are the main risk group for co-infection (Desjeux \& Alvar 2003), yet IVDU accounts for only $6 \%$ of the HIV patients in MS. The increased occurrence of IVDU led to the idea that the anthroponotic cycle (Cruz et al. 2006) could play a relevant role in the transmission of both infections in this region. Investigating this causal relationship has great importance for defining prevention strategies, taking into consideration the transmission patterns in a Brazilian endemic area.

VL was the first opportunistic infection in $60.1 \%$ of the HIV/AIDS cases evaluated in the present study; in $43 \%$ of the cases, both diseases were diagnosed concomitantly. However, a relevant number of patients ( 8 cases) presented VL only years after HIV diagnosis, which can reflect the relatively recent introduction of $\mathrm{VL}$ in MS (Oliveira et al. 2006, Brustoloni et al. 2007). Patients had low levels of $\mathrm{CD}^{+}$T-cells and most of them maintained detectable plasmatic HIV viral load even under HAART. These findings suggested that both infections would contribute to impair the effector immune function and consequently the ability to suppress the viral load. Overall, these data reinforced the idea that HIV/AIDS can be a predisposing condition for VL (Cacopardo et 
al. 1996, Wolday et al. 1999, Barreto-de-Souza et al. 2006, Alvar et al. 2008) and the hypothesis that VL can be a predisposing condition for HIV/AIDS progression should also be considered. Therefore, improving the epidemiological surveillance of HIV infection among VL patients may lead to a precocious diagnosis before the onset of severe immunodeficiency.

Note that the main clinical manifestations reported in our study (fever, hepatoesplenomegaly and weight loss) were similar to those observed for VL in non-HIV infected patients and for the Mediterranean VL-HIV/ AIDS cases. Fever occurred in all cases in the series described here and was described in $67 \%$ of the patients in a study from the Brazilian Northeast Region (Daher et al. 2009) and in $75 \%$ of European co-infected patients in another study (Cruz et al. 2006). Enlargement of the liver and especially the spleen seems to be less frequent in VL-HIV/AIDS patients than in VL patients without AIDS (Pintado et al. 2001) and this enlargement may be associated with a deficient proliferative response of mononuclear cells in these organs (Peters et al. 1990). Atypical manifestations at unusual anatomic sites such as skin, gastrointestinal tract or lungs (Orsini et al. 2002, Herrejón et al. 2005) were not observed in this study.

Identifying VL cases in AIDS patients can be difficult because some drugs used to treat opportunistic infections or even HIV itself may be leishmanicidal and can affect the performance of parasitological methods (Savoia et al. 2005). Despite having clinical evidence of VL, seven patients were excluded from this study and only 23 parasitological confirmed cases were included. Even in patients known to be infected, as demonstrated by isolating parasites by culture, the direct examination of bone marrow smears failed to confirm the infection in three patients. This discrepancy indicates that a gold-standard method for VL diagnosis may not detect all cases of leishmaniasis, particularly disease in HIV/ AIDS patients.

Developing a more effective therapeutic scheme for VL-HIV/AIDS patients and enhancing the benefits of secondary prophylaxis drugs to prevent relapses remain a challenge for researchers (Laguna 2003, Rosenthal \& Marty 2003, Alvar et al. 2008). In this study, pentavalent antimony and amphotericin B deoxycholate were the drugs of choice and were prescribed according to Brazilian guidelines. The efficacy of the therapeutic approach could not be ascertained, although the lethality among the patients studied was low in comparison to that in other reports (Bourgeois et al. 2008, ter Horst et al. 2008). Antimonial toxicity is increased in HIV patients and pancreatitis, renal failure and myocarditis were the most commonly reported adverse effects. The antimonial was efficacious for five patients, but the drug was discontinued in 12 cases due to therapeutic failure (5 cases) or precocious increase in amylase levels ( 7 cases). Since the risk factors for predicting side effects are unknown, we cannot rule out that the approach was a precocious discontinuation of the antimonial. Here amphotericin $\mathrm{B}$ deoxycholate seemed to be more efficacious than the pentavalent antimony, although clinical trials failed to show differences in cure rates of VL in HIV-infected pa- tients (Laguna 2003). Other drugs such as amphotericin B in lipid formulation may be promising (Berman 1999, Sundar et al. 2006, Alvar et al. 2008).

A patient's severely immunocompromized state may account for the tissue parasite maintenance and predisposition to frequent relapses observed in VL-associated HIV/AIDS-patients (ter Horst et al. 2008). VL patients without associated conditions tended to regain tissue lymphopoietic functions soon after anti-leishmanial therapy (Carvalho et al. 1994). Conversely, in our study, in spite of HAART and satisfactory anti-leishmanial therapy, no significant increase in $\mathrm{CD}^{+} \mathrm{T}$-cells was observed in VL-HIV/AIDS patients even during clinical remission. Baseline CD4 ${ }^{+}$T-cells under 100 cells $/ \mathrm{mm}^{3}$ and poor $\mathrm{CD}^{+} \mathrm{T}$ count recovery despite HAART were considered risk factors for relapse and death in co-infected patients in Ethiopia (ter Horst et al. 2008). Thus, the high rate of relapses could be associated with the inability to control parasite replication due to impaired reconstitution of the Leishmania-specific lymphocyte repertoire. These features could provide a rational for introducing secondary prophylaxis (Bourgeois et al. 2008).

According to our findings, AIDS-associated VL patients from urban areas of MS seem to share clinical aspects with those from European endemic regions, suggesting that the parasite species circulating in these regions do not influence the clinical course of the disease. The prevalence of IVDU among co-infected patients in MS indicates that this route of transmission can have a relevant epidemiological impact on both diseases. Therefore, our results call for further AIDS-associated VL epidemiological research targeting the history of exposure in endemic areas with different epidemiological characteristics. Focusing on these specific factors will improve the surveillance of VL-HIV/AIDS patients.

\section{ACKNOWLEDGEMENTS}

To Laboratório de AIDS e Imunologia Molecular, IOC-Fiocruz, and to Programa de Leishmanioses, SVS, MS, Brazil.

\section{REFERENCES}

Alvar J, Aparicio P, Aseffa A, Den Boer M, Cañavate C, Dedet JP, Gradoni L, ter Horst R, López-Vélez R, Moreno J 2008. The relationship between leishmaniasis and AIDS: the second 10 years. Clin Microbiol Rev 21: 334-359.

Alvar J, Cañavate C, Gutiérrez-Solar B, Jiménez M, Laguna F, LópezVélez R, Molina R, Moreno J 1997. Leishmania and human immunodeficiency virus coinfection: the first 10 years. Clin Microbiol Rev 10: 298-319.

Barreto-de-Souza V, Pacheco GJ, Silva AR, Castro-Faria-Neto HC, Bozza PT, Saraiva EM, Bou-Habib DC 2006. Increased Leishmania replication in HIV-1-infected macrophages is mediated by tat protein through cyclooxygenase- 2 expression and prostaglandin E2 synthesis. J Infect Dis 194: 846-854.

Berman JD 1999. US Food and Drug Administration approval of AmBisome (liposomal amphotericin B) for treatment of visceral leishmaniasis. Clin Infect Dis 28: 49-51.

Borges AS, Machado AA, Ferreira MS, de Castro Figueiredo JF, Silva GF, Cimerman S, Bacha HA, Teixeira MC 1999. Concurrent leishmaniasis and human immunodeficiency virus (HIV) infection: a study of four cases. Rev Soc Bras Med Trop 32: 713-719. 
Bourgeois N, Lachaud L, Reynes J, Rouanet I, Mahamat A, Bastien P 2008. Long-term monitoring of visceral leishmaniasis in patients with AIDS: relapse risk factors, value of polymerase chain reaction and potential impact on secondary prophylaxis. $J$ Acquir Immune Defic Syndr 48: 13-19.

Brustoloni YM, Lima RB, da Cunha RV, Dorval ME, Oshiro ET, de Oliveira ALL, Pirmez C 2007. Sensitivity and specificity of polymerase chain reaction in Giemsa-stained slides for diagnosis of visceral leishmaniasis in children. Mem Inst Oswaldo Cruz 102: 497-500.

Cacopardo B, Nigro L, Preiser W, Famá A, Satariano MI, Braner J, Celesia BM, Weber B, Russo R, Doerr HW 1996. Prolonged Th2 cell activation and increased viral replication in HIV-Leishmania co-infected patients despite treatment. Trans $R$ Soc Trop Med Hyg 90: 434-435.

Carvalho EM, Bacellar O, Brownell C, Regis T, Coffman RL, Reed SG 1994. Restoration of IFN-gamma production and lymphocyte proliferation in visceral leishmaniasis. J Immunol 152: 5949-5956.

Cruz I, Nieto J, Moreno J, Cañavate C, Desjeux P, Alvar J 2006. Leishmania/HIV co-infections in the second decade. Indian J Med Res 123: 357-388.

Daher EF, Fonseca PP, Gerhard ES, Leitão TM, Silva Júnior GB 2009. Clinical and epidemiological features of visceral leishmaniasis and HIV co-infection in fifteen patients from Brazil. $J$ Parasitol 95: 652-655.

del Giudice P, Mary-Krause M, Pradier C, Grabar S, Dellamonica P, Marty P, Gastaut JA, Costagliola D, Rosenthal E 2002. Impact of highly active antiretroviral therapy on the incidence of visceral leishmaniasis in a French cohort of patients infected with human immunodeficiency virus. J Infect Dis 186: 1366-1370.

Desjeux P, Alvar J 2003. Leishmania/HIV co-infections: epidemiology in Europe. Ann Trop Med Parasitol 97 (Suppl. 1): 3-15.

Evans TG, Teixeira MJ, McAuliffe IT, Vasconcelos I, Vasconcelos AW, Sousa A de A, Lima JW, Pearson RD 1992. Epidemiology of visceral leishmaniasis in Northeast Brazil. J Infect Dis 166: 1124-1132.

Herrejón A, Cervera A, Maciá M, Ferrer R, Blanquer R 2005. Bronchioloalveolar adenoma associated with bronchiolitis obliterans and leishmaniasis with lung involvement in acquired immunodeficiency syndrome. Arch Bronconeumol 41: 233-235.

Laguna F 2003. Treatment of leishmaniasis in HIV-positive patients. Ann Trop Med Parasitol 97 (Suppl. 1): 135-142.

Marques N, Cabral S, Sá R, Coelho F, Oliveira J, Saraiva da Cunha JG, Meliço Silvestre A 2007. Visceral leishmaniasis and HIV infection in the HAART era. Acta Med Port 20: 291-298.

MS - Ministério da Saúde/Secretaria de Vigilância em Saúde 2004a. Manual de recomendações para diagnóstico, tratamento e acompanhamento da co-infecção Leishmania-HIV, Brasília. Programa
Nacional de DST/HIV/Aids. Available from: portal.saude.gov.br/ portal/arquivos/pdf/manual_leish_hiv.pdf.

MS - Ministério da Saúde/Secretaria de Vigilância em Saúde 2004b. Critérios para definição de casos de AIDS em adultos e crianças. Programa Nacional de DST/HIV/Aids. Available from: aids.gov. br/data/documents.

Oliveira AL, Paniago AM, Dorval ME, Oshiro ET, Leal CR, Sanches M, Cunha RV, Bóia MN 2006. Emergent outbreak of visceral leishmaniasis in Mato Grosso do Sul state. Rev Soc Bras Med Trop 39: 446-450.

Olivier M, Badaró R, Medrano FJ, Moreno J 2003. The pathogenesis of Leishmania/HIV co-infection: cellular and immunological mechanisms. Ann Trop Med Parasitol 97 (Suppl. 1): 79-98.

Orsini M, Silva M, Luz ZM, Disch J, Fernandes O, Moreira D, Guedes AC, Rabello A 2002. Identification of Leishmania chagasi from skin in Leishmania/HIV co-infection: a case report. Rev Soc Bras Med Trop 35: 259-262.

Pasquau F, Ena J, Sanchez R, Cuadrado JM, Amador C, Flores J, Benito C, Redondo C, Lacruz J, Abril V, Onofre J 2005. Leishmaniasis as an opportunistic infection in HIV-infected patients: determinants of relapse and mortality in a collaborative study of 228 episodes in a Mediterreanean region. Eur J Clin Microbiol Infect Dis 24: 411-418.

Peters BS, Fish D, Golden R, Evans DA, Bryceson AD, Pinching AJ 1990. Visceral leishmaniasis in HIV infection and AIDS: clinical features and response to therapy. $Q J$ Med 77: 1101-1111.

Pintado V, Martín-Rabadán P, Rivera ML, Moreno S, Bouza E 2001. Visceral leishmaniasis in human immunodeficiency virus (HIV)infected and non-HIV-infected patients. A comparative study. Medicine (Baltimore) 80: 54-73.

Rabello A, Orsini M, Disch J 2003. Leishmania/HIV co-infection in Brazil: an appraisal. Ann Trop Med Parasitol 97 (Suppl. 1): 17-28.

Rosenthal E, Marty P 2003. Recent understanding in the treatment of visceral leishmaniasis. $J$ Postgrad Med 49: 61-68.

Savoia D, Allice T, Tovo PA 2005. Antileishmanial activity of HIV protease inhibitors. Int J Antimicrob Agents 26: 92-94.

Sundar S, Jha TK, Thakur CP, Bhattacharya SK, Rai M 2006. Oral miltefosine for the treatment of Indian visceral leishmaniasis. Trans R Soc Trop Med Hyg 100 (Suppl. 1): S26-33.

ter Horst R, Collin SM, Ritmeijer K, Bogale A, Davidson RN 2008. Concordant HIV infection and visceral leishmaniasis in Ethiopia: the influence of antiretroviral treatment and other factors on outcome. Clin Infect Dis 46: 1702-1709.

Wolday D, Akuffo H, Demissie A, Britton S 1999. Role of Leishmania donovani and its lipophosphoglycan in $\mathrm{CD} 4^{+} \mathrm{T}$-cell activationinduced human immunodeficiency virus replication. Infect Immun 67: 5258-5264. 